\title{
Mundo militante: algunas caracterizaciones de la militancia en la provincia de Jujuy, Argentina
}

\author{
Militant World: some characterizations of militancy \\ in the province of Jujuy, Argentina
}

\author{
Adrián Pablo Berardi-Spairani \\ CONICET/IDAES-UNSAM \\ adrianberardi@gmail.com \\ https://orcid.org/0000-0003-4269-7400
}

\begin{abstract}
Resumen
El presente trabajo analiza el mundo militante por medio del estudio de la carrera militante retomando la perspectiva de carrera de Howard Becker. El objetivo es dar cuenta de cómo se construye y desarrolla ese mundo a través de las experiencias de militantes de distintos espacios de participación política.
\end{abstract}

Se propone indagar en las lógicas compartidas por los militantes de la provincia de Jujuy, Argentina, a partir de comprender la manera en que interactúan más allá de su espacio o ámbito de pertenencia, retomando una perspectiva microestructural. Se pretende entender la militancia contemporánea superando las limitaciones de los estudios macroestructurales, principalmente aceptando que en la actualidad existe una diversidad en las formas y espacios de militancia, que rompe con las fronteras de la militancia más estructural y tradicional de partidos y sindicatos.

Para alcanzar estos objetivos, se realizó un análisis longitudinal de trayectorias de nueve militantes de diversos espacios de participación política de Argentina, considerando los aspectos subjetivos y objetivos a partir del relato de los propios militantes por medio del uso de la técnica del relato de vida.

Este trabajo permite dar cuenta del aporte analítico del "mundo militante" para exponer las continuidades y rupturas, así como las generalidades y particularidades de la militancia contemporánea en Argentina.

\section{Palabras clave}

Activismo, Argentina, carrera militante, compromiso político, mundo militante, participación política.

Forma sugerida de citar: Berardi-Spairani, A.P. (2020). Mundo militante: algunas caracterizaciones de la militancia en la provincia de Jujuy, Argentina. Universitas, 33, pp. 181-200. 


\begin{abstract}
The present work analyses the militant world through the study of the militant career by taking up Howard Becker's career perspective. The objective is to give an account of how this world is constructed and developed through the experiences of militants from different spaces of political participation.

In this way, it proposes to investigate the shared logics of the militants of the province of Jujuy, Argenti$n a$, from understanding the way in which they interact beyond their space or sphere of belonging, taking up again a microstructural perspective. The aim is to understand contemporary militancy by overcoming the limitations of macro-structural studies, mainly by accepting that there is currently a diversity of forms and spaces of militancy, which breaks with the borders of the more structural and traditional militancy of parties and unions.

To achieve these objectives, a longitudinal analysis of the trajectories of five militants from different spaces of political participation in Argentina was carried out, considering the subjective and objective aspects based on the narrative of the militants themselves through the use of the life story technique.

This work allows us to give an account of the analytical contribution of the "militant world" to expose the continuities and ruptures, as well as the generalities and particularities of contemporary militancy in Argentina.
\end{abstract}

\title{
Keywords
}

Activism, Argentina, militant career, political commitment, militant world, political participation

\section{Introducción}

Fillieule y Accornero (2016) afirman que los cambios en las formas del compromiso político y la diversidad de las prácticas militantes contemporáneas obligaron a las ciencias sociales a desplazar los estudios de niveles macroestructurales (estudio de los partidos políticos o los sindicatos) hacia estudios microestructurales relacionados, por ejemplo, a las trayectorias individuales. Estos trabajos dieron cuenta de la militancia como un proceso dinámico donde el involucramiento y el compromiso pueden ser parcial o total, a corto o a largo plazo. Es decir, junto con la militancia tradicional, se desarrolla un nuevo tipo de militancia distanciada (Pudal, 2011) producto de los cambios políticos, sociales y económicos a nivel global (Berardi-Spaira- 
ni, 2020a), que llevan a la emergencia de nuevos espacios de participación y diversos compromisos políticos, que incluso se desarrollan al mismo tiempo, a causa de la emergencia de nuevas y diversas demandas.

Los trabajos sobre la militancia en Argentina han sido fragmentarios, la mayoría de las investigaciones se centró en las condiciones estructurales de los espacios de participación o las olas de protesta, recuperando una cla-

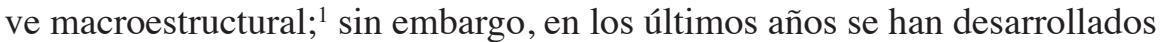
análisis desde una perspectiva microestructural, ${ }^{2}$ incluso retomando la perspectiva de carrera militante. ${ }^{3}$

Partiendo de estos antecedentes, este trabajo propone analizar la militancia desde un nivel microestructural, su objetivo central es dar cuenta del mundo militante a partir del estudio de la carrera militante (Agrikoliansky, 2007), e indagar la manera en que los militantes reafirman la existencia de ese mundo más allá del tiempo.

Este trabajo analiza la manera en que los sujetos se involucran en la militancia, cuáles son los factores que determinan la inscripción en este tipo de actividad y su sostenimiento en el tiempo.

Esto lleva a indagar las diferencias o similitudes entre los militantes de distintos ámbitos de participación política; aquí se pregunta cuáles son los elementos en común que mantienen cada uno de ellos, y si a pesar de las diferencias (tradiciones u objetivos) existe un conjunto de lógicas y regularidades (aprendizajes, prácticas militantes, jerarquías al interior de los espacios de participación) que son compartidas por todos los militantes.

Para llevar adelante este trabajo se recuperó el concepto de "mundo" formulado por Becker (2008). Si bien este concepto fue acuñado a partir de la idea del arte, en este trabajo se consideró que es aplicable al estudio de la militancia, porque tanto en el arte como en la militancia sus integrantes tienen orígenes diversos, lo que genera una fuerte heterogeneidad en su interior; y además, porque si bien existe un conjunto de actividades y lógicas tradicionales (que constituyen un conjunto de acuerdos denominados "convenciones") que son incorporadas por medio del aprendizaje, tanto la diversidad de los integrantes como el desarrollo de sus prácticas, que surgen

1 Entre esos trabajos se destacan: Jelin (1985), Svampa y Pereyra (2004), Pereyra (2008), Murillo (2013); Vommaro et al. (2015).

2 Entre otros, Giorgi (2014), Lodola (2009) y Levita (2015).

3 Entre otros, Vázquez (2010), Zenobi y Pereyra (2015), Berardi-Spairani (2017) y Pereyra y Berardi (2020). 
en contextos específicos, permiten proponer nuevas lógicas que entran en discusión con las ya existentes. Así el mundo militante puede considerarse como una red de personas que desarrollan un tipo de actividad corporativa y que se encuentran vinculadas por medio de un conjunto de "convenciones", que no son rígidas y que tienden a modificarse a partir del desarrollo de la propia actividad militante (Berardi-Spairani, 2017).

En el caso argentino, a partir de la década del noventa, las prácticas militantes comenzaron a verse alteradas principalmente con el surgimiento de nuevos espacios de participación, por ejemplo, las organizaciones de desocupados. De esta forma, los activistas de estas organizaciones desarrollaron nuevas prácticas político-militantes que convivían con otras más tradicionales (Auyero, 2002; Frederic, 2004; Quirós, 2006). A partir de esto, se puede sostener que las "convenciones" no deben pensarse como rígidas e inmutables; por el contrario, el quehacer militante lleva a (re)interpretarlas, ponerlas en discusión o (re)inventarlas.

Entonces, el concepto de "mundo militante" permite interpretar la práctica militante comprendiendo que las acciones que se desarrollan tienen un alto grado de libertad, al mismo tiempo que los militantes cooperan y/o compiten dentro de ese mundo, favoreciendo el surgimiento de nuevas actividades producto de nuevos espacios de participación, nuevas demandas y cambios en los clivajes políticos. Sin embargo, esto no genera necesariamente nuevos mundos dado que hay ciertas recurrencias que se mantienen; por ejemplo, las formas de ingreso a la militancia, el proceso de aprendizaje que atraviesan los militantes, el rol de los militantes experimentados y el desarrollo de una construcción política.

Así, el "mundo militante" como una herramienta analítica permite observar las secuencias que atraviesa una carrera militante, dando cuenta de la continuidad de formas de cooperación tradicionales, además de aquellas que son incorporadas a partir de las nuevas formas de acción.

Por otra parte, si bien la actividad militante podría analizarse aplicando el concepto bourdieusiano de campo, en este trabajo se considera que el concepto de mundo tiende a ser un instrumento más dinámico y completo para ese objetivo, principalmente porque permite entender la militancia como un proceso dinámico donde sus actores constituyen un corpus totalmente heterogéneo al igual que sus prácticas. Sin embargo, el concepto de campo de Bourdieu está definido por un conjunto de "relaciones objetivas" (Bourdieu, 1989, p. 3) que se encuentran determinadas y/o condicionadas por el 
habitus, ${ }^{4}$ que ubica a los sujetos dentro de un espacio social, y cuyas prácticas están establecidas por la estructura de pertenencia.

Es decir, las relaciones que se generan son condicionadas por el habitus, que determina las propias exigencias del campo. Las prácticas (y las relaciones) que se producen al interior del campo son fijadas por propias estructuras - rígidas - del campo, donde la acumulación del capital (social, político, etc.) y la experiencia dentro de él permiten el desarrollo de las prácticas.

La rigidez que proponen los conceptos de campo/habitus no permite interpretar de manera plena las dinámicas y los cambios que genera el propio proceso militante, como la emergencia de nuevas prácticas o espacios de participación, o incluso el involucramiento de sujetos provenientes de distintos sectores del espacio social.

Por otra parte, aquí se retomará la perspectiva de carrera desarrollada por Becker (2012) que propone analizar las trayectorias de las personas, tomando en cuenta los aspectos subjetivos y objetivos que atraviesa el sujeto, considerando que cada secuencia es resultado de la anterior y condición de posibilidad de la siguiente, dando lugar a un modelo procesual para el estudio del compromiso político (Fillieule, 2001). Este artículo sugiere dar cuenta de la militancia sin centrarse en el análisis de una organización determinada o ciclo de protesta específico; el interés está puesto en demostrar que existe un mundo militante donde sus integrantes comparten ciertas regularidades y secuencias comunes más allá de sus diferentes posicionamientos, recuperando la perspectiva de los estudios franceses sobre la militancia y el activismo (Agrikoliansky, 2007). Este trabajo se centra específicamente en el análisis de tres etapas compartidas por los militantes: 1) inicio de la militancia, 2) aprendizaje y 3) construcción política.

Por otra parte, esta propuesta no pretende llevar adelante una generalización; por el contrario, aspira a poner en discusión nuevas formas de abordar los estudios de la militancia partiendo del análisis de la militancia política en una provincia argentina.

Metodológicamente se adoptó un abordaje de tipo cualitativo por medio de entrevistas en profundidad a militantes políticos de la provincia de Jujuy, Argentina, utilizando la técnica del relato de vida (Kornblit, 2007). Los relatos de vida permitirán dar cuenta de los momentos que atravesó el militan-

4 Por habitus debe entenderse "sistema de disposiciones duraderas [...] principios generadores y organizadores de prácticas” (Bourdieu, 2007, p. 86). 
te, recuperando la construcción de la narrativa del yo, dando cuenta de los puntos de inflexión que determinaron el compromiso. Es decir, que a partir de su propia narración el militante hace "comprensible su mundo" (Meccia, 2012 , p. 41), por medio de su devenir biográfico, pero también de las relaciones con "sus semejantes y sus entornos sociales" (Meccia, 2015, p. 15).

Este tipo de herramienta permite observar la dimensión temporal y el desarrollo del militante, mostrando los distintos acontecimientos por los que atravesó el sujeto militante, constituyéndolo como el narrador de la historia de la sociedad de la que forma parte (Saltalamacchia, 1987; Della Porta, 2014); recuperar no solo la percepción de los sujetos respecto a los hechos sino también los elementos que intervinieron en el momento en que desarrollaba la acción (Becker, 2009). De esta forma, este estudio se desarrolla a partir de una interconexión entre la mirada de los actores respecto a su propia carrera militante y el análisis del investigador por medio de un proceso de reflexividad (Burawoy, 1998).

Para el desarrollo de este artículo se utilizó un corpus de nueve entrevistas a militantes-dirigentes de diversas organizaciones de la provincia de Jujuy, que fueron realizadas entre los años 2014 y 2017. ${ }^{5}$ Los casos que aquí se presentan fueron seleccionados considerando que 1) los militantes hayan iniciado su militancia entre los años 1990 y 2000, época en la que en Argentina no solo surgieron nuevos espacios de participación, como las organizaciones de desocupados, sino que además los espacios tradicionales como los sindicatos o partidos atravesaron por transformaciones, fracturas y alianzas; y 2) que los militantes hayan alcanzado un grado de dirigente. Esta condición no solo permite comparar cada una de las carreras militantes, sino también observar las instancias que atraviesan dentro de las jerarquías al interior de la militancia.

\section{La adscripción al mundo militante}

Según la perspectiva de Diani (2004), el ingreso a la militancia está condicionado por las redes sociales que posee el sujeto, estos vínculos (familiares, barriales o amistades) no solo representan los procesos de socialización política (Dubet, 1994), son también el puente entre el futuro militante y la

5 Los relatos de militantes que componen este trabajo forman parte de una investigación más amplia respecto a la carrera militante en la provincia de Jujuy, Argentina, en la que se realizaron más de 50 entrevistas en profundidad a militantes sociales, partidarios y sindicales. 
oferta de participación militante disponible ${ }^{6}$ (Klandermans, 2004). Es decir, no alcanza con una predisposición personal o psicológica para militar, es fundamental tener los nexos necesarios que garanticen ese ingreso.

De esta manera, el proceso de iniciación militante puede estar sujeto a distintas variables, principalmente condicionado por factores externos al sujeto. En algunos casos el sujeto ingresa al mundo militante participando en el reclamo de una demanda específica, estableciendo un tipo de compromiso político parcial a partir de su intervención en asambleas, marchas, actividades culturales e incluso en la organización de la ocupación del espacio público, pero una vez que la demanda fue satisfecha o derrotada, el militante abandona su participación. ${ }^{7}$

También existen otros casos donde los sujetos se incorporan a la militancia por medio de una pequeña participación (repartir volantes, formar parte de una protesta o asamblea) y comienzan sustantivamente a aumentar su compromiso e involucramiento con el espacio de pertenencia, principalmente condicionados por las redes sociales que se tejen en esos espacios (McAdam, 1982). En ese momento, se inicia un proceso de aprendizaje y la configuración de nuevos vínculos al interior de su organización y del mundo militante.

Las carreras militantes analizadas nos permiten mostrar que las redes interpersonales se constituyen como fundamentales y se configuran como iniciadores o promotores de esa participación.

Uno de los principales vínculos que permiten un acercamiento a la militancia es la familia. Distintos militantes dan cuenta de la importancia de sus vínculos afectivos, las familias principalmente tienden a ser claves en el proceso de iniciación militante y socialización política (Vázquez (2010):

Yo creo que tengo sangre política, digamos, por historias familiares, siempre estuve involucrado en la política de alguna u otra manera, siempre acompañé a mi padre en la política, en los actos políticos, en reuniones, muchas veces reuniones de la juventud, sin entender nada, acompañaba a los actos políticos, escuchaba discursos, estaba cerca. (Pablo, Partido Justicialista, septiembre de 2016)

6 Esta se encuentra sujeta a las trasformaciones que se dan en los clivajes y contextos sociopolíticos (Canelo, 2001 y Berardi-Spairani, 2018a).

7 En este trabajo proponemos analizar trayectorias de militantes que alcanzaron altos grados de compromiso político. Sin embargo, según Pudal (2011), es posible identificar nuevas formas de militancias distanciadas a partir de compromisos puntuales ante ciertas causas que interpelan al activista como sujeto. 
En otros casos, los espacios de socialización secundarios como la escuela, el trabajo o el barrio son los que juegan un rol central en el momento del establecimiento del compromiso político-militante, si bien existen diversas formas de acercamiento a la militancia:

Cuando comienzo a estudiar Antropología, me acerqué a una agrupación estudiantil [...] porque me hago amigo de compañeros que militaban ahí, así que ahí fue por una cuestión más de amistad el acercamiento. (Martín, Corriente Clasista y Combativa/Asociación de Trabajadores del Estado, septiembre de 2016)

[Yo] era un trabajador golondrina [...], algunas veces robaba para comer, [en ese tiempo] unas vecinas del paraje nos llevan para empezar a organizarse como un grupo, como organización, [y] empezamos con la copa de leche ${ }^{8}$ para los chicos del barrio. (Patricio, Organización Barrial Tupac Amarú, noviembre de 2015)

Me vinculé al sindicato principalmente por mi trabajo, un compañero me invita a participar e integrar la lista, y bueno, entré, participé y empecé siendo vocal. (Blanca, Unión Trabajadores de Entidades Deportivas y Civiles, septiembre de 2016)

En perspectiva a lo que sostiene Diani (2004), Dubet (1994) y McAdam (1982), estos relatos muestran cómo el ingreso al mundo militante está determinado por lo que podríamos denominar facilitadores; el amigo, el vecino, los padres son los vínculos que poseen los sujetos antes de ser militantes, y generan un marco de posibilidad para el ingreso a la militancia. El involucramiento político no está determinado solo por los intereses (que pueden ser clave) sino por las redes interpersonales.

\section{El reconocimiento del mundo militante}

$\mathrm{Al}$ interior del mundo, el militante atraviesa un proceso de aprendizaje; si bien como sostienen los militantes entrevistados, el aprendizaje constituye una característica constante en la práctica política, tiene un carácter fun-

8 La copa de leche hace referencia a un conjunto de merenderos que organizaciones sociales argentinas pusieron en marcha a partir de la década del noventa, con el objetivo de garantizar algún tipo de alimentación a los chicos de familias empobrecidas ante la falta de respuesta del Estado. 
damental al momento en que el sujeto confirma su compromiso político e interactúa en el mundo militante.

Ese aprendizaje tiene dos vertientes: una, vinculada al proceso de influencia de los experimentados (Becker, 2012), referentes o dirigentes del espacio de participación, que trasmiten conocimientos, experiencias y, en cierto punto, disciplina. La otra, relacionada a la propia práctica militante.

El militante experimentado es quien trasmite los conocimientos sobre las lógicas, normas, regularidades y los sentidos de la militancia; así, en el accionar político, acompañando a los dirigentes, el militante va incorporando conocimientos y prácticas que son propias de ese mundo. La trasmisión puede ser oral, pero también en la misma acción política.

Para activarse en algo primero tiene que haber un paso previo que creo que es escuchar y aprender, porque a la política se la hace al andar, pero también es importante escuchar, llenarse de valores, tener referentes políticos que te ayuden a tener miradas diferentes del mundo. (Pablo, Partido Justicialista, septiembre de 2016)

Escuchar en el mundo militante es sinónimo de aprender y se refiere a incorporar lógicas que luego se ponen en marcha en la práctica política. Pero el aprendizaje también se inscribe en un proceso de interacción con los otros $^{9}$ y configura un proceso de interiorización de métodos sin los cuales la carrera militante se vería limitada y condicionaría el quehacer militante. Así, el diálogo y los intercambios con otros militantes permiten el acceso a saberes fundamentales para la práctica, pero también el reconocimiento y la competencia al interior del mundo militante.

Uno aprende no solo de sus compañeros y referentes, sino también [...] se aprende mucho porque uno va viendo las otras diferentes agrupaciones, vas recién entendiendo por qué hay muchas agrupaciones, cómo es que se mueven, cuáles son los planes y las políticas que pretenden [...], ahí uno entiende. (Martín, Corriente Clasista y Combativa/Asociación de Trabajadores del Estado, septiembre de 2016)

Cuando vos militas tenés que estar dispuesto a escuchar a los otros militantes, si crees que te las sabes todas perdiste [...], aprendes al interior de la or-

9 Como sostiene Morán (2011), es importante entender que el proceso de aprendizaje se desarrolla también en el proceso de socialización política. 
ganización, pero también afuera, en cada actividad, en cada marcha. (Patricio, Organización Barrial Tupac Amarú, septiembre de 2016)

El proceso de aprendizaje es dinámico y está sujeto a la práctica militante, en la que se crean nuevos canales de vinculación con otros militantes, se proponen nuevas iniciativas de participación y repertorios de acción política; pero también los marcos ideológicos o doctrinarios que determinan las particularidades de cada espacio de participación. El aprendizaje aparece entonces como el resultado de ambos elementos que entran en conflicto al interior del mundo militante, incentivando nuevos procesos de aprendizaje.

La militancia termina siendo una cuestión dialéctica, o sea, el convencimiento ideológico te lleva a determinadas prácticas, y en el desarrollo de esa práctica también vas tomando elementos nuevos que van también modificando la cuestión ideológica [...], vas incorporando nuevas cosas. (Rodrigo, Asociación de Trabajadores Desocupados de Jujuy, septiembre de 2016)

La capacidad de organizarnos y de poner en práctica en definitiva todo lo que uno aprendía o lo que uno decía que era la doctrina, las convicciones, de ponerlas en práctica [...] lo vas incorporando cuando empezás a militar. (Cecilia, Partido Justicialista, septiembre de 2016)

Si bien la influencia de los experimentados tiende a ser clave, las trasformaciones sociales y económicas, los cambios en los clivajes políticos y la incorporación de nuevos actores al mundo militante permiten el surgimiento de nuevas miradas respecto a la militancia y pone en cuestión "las lógicas", generando experiencias novedosas producto de nuevos formatos de acción política.

Los nuevos ingresantes al mundo militante discuten en torno a la tradición, las identidades y las lógicas, creando nuevas, solapando o reemplazando las viejas. Y, en este sentido, el reconocimiento del mundo tiende a configurarse por una secuencia compuesta por el diálogo con otros militantes, las nuevas experiencias militantes y el compromiso político. Pero también están en juego los contextos que determinan las trayectorias de cada uno de los militantes (Berardi-Spairani, 2018a) y generan controversias en relación con el statu quo del mundo militante. Esta situación es reflejada principalmente por los jóvenes militantes:

Los jóvenes no solo incorporan la experiencia de los dirigentes, también generamos nuevos espacios que discuten con las tradiciones [...], nacimos y 
vivimos en épocas distintas, pero a pesar de las diferencias, trabajamos para objetivos comunes. (Marta, Partido Justicialista, septiembre de 2016)

\section{La vida militante y la construcción política}

El momento de reconocimiento del mundo militante es también un momento de sedimentación del compromiso político y de una carrera militante. Sin embargo, incluso cuando haya altos niveles de compromiso, la actividad puede abandonarse, un sujeto puede dejar de ser militante. Entonces la pregunta es ¿cuáles son los factores que garantizan la continuidad de la militancia en el tiempo?

La discusión no se resume solo en el sostenimiento del compromiso, sino también en la reproducción y subsistencia del militante al interior del mundo militante. A partir de las trayectorias analizadas, es posible afirmar que el sostenimiento de la militancia tiene condicionantes claves: los ingresos económicos, la profesionalización de la militancia ${ }^{10}$ y la construcción política (Berardi-Spairani, 2018b).

A partir de los relatos, se puede afirmar que la militancia es un tipo de actividad de la que no se espera una retribución económica, ${ }_{11}^{11}$ pero su reproducción requiere la disposición de tiempo para llevarla adelante; por tanto, es necesario el desarrollo de un tipo de actividad que garantice recursos económicos sin limitar el tiempo disponible para la actividad militante.

En ese sentido, todos los militantes entrevistados sostienen que la militancia es un tipo de actividad de tiempo completo donde "poner el cuerpo" 12 es una característica clave, y hacen referencia a dejar cosas de la vida cotidiana para dedicar tiempo a la militancia: "Con la militancia fui dejando cosas, incluso tiempo con mi familia, con mi hijo" (Entrevista a dirigente social y sindical, septiembre de 2016).

10 Retomando el trabajo de Berardi-Spairani (2017), entendemos que la profesionalización de la militancia no debe igualarse al político profesional, sino más bien a la capacidad del militante de vivir de recursos provenientes de la actividad militante.

11 Sobre este tema ver Gaxie (1977).

12 "Poner el cuerpo" es una categoría nativa que surgió en las distintas entrevistas realizadas, por medio de la que los militantes dan cuenta que la militancia no tiene hora, ni lugar; es una actividad a tiempo completo donde el sujeto debe estar siempre disponible. Sin embargo, no es una categoría novedosa, como sostiene Peller (2018), "poner el cuerpo" constituye una expresión que proviene de la militancia setentista en Argentina. 
Los distintos relatos militantes muestran que la garantía de acceso a recursos económicos que permitan la subsistencia dentro del mundo militante (y fuera de él), esa dedicación a tiempo completo, proviene de los vínculos generados en la propia actividad militante. En algunos casos, los recursos económicos se consiguen ingresando como empleado en las estructuras del Estado, siendo electo concejal o diputado, o incluso siendo beneficiario de algún tipo de programa o plan social:

Empecé [...] a trabajar en [un organismo del] Estado, [y después], me propusieron ser candidato a diputado provincial. (Pablo, Partido Justicialista, septiembre de 2016)

Como ingeniero agrónomo [...] me incorporé como técnico en la Subsecretaría de Agricultura Familiar de la Nación, [esto] me permitió generar nuevos vínculos con otras organizaciones [sociales]. (Juan, Movimiento Evita Jujuy, marzo de 2016)

Militando dentro de la universidad [...] también era cuando estaba en [la organización social], empecé a cobrar un plan social, ${ }^{13}$ [...] tenía que contraprestar el servicio, sería, tener que cumplir horas, o sea que empecé a trabajar, mientras militaba [...] armamos una agrupación [sindical que integró a los beneficiaros de esos planes] y nos incorporamos a la lista del sindicato de trabajadores estatales. (Martín, Corriente Clasista y Combativa/Asociación de Trabajadores del Estado, septiembre de 2016)

Los relatos dan cuenta que el acceso a esos recursos económicos puede ser por la expertise, el status militante o reconocimiento público y/o el padrinazgo de otros dirigentes. Esos recursos económicos algunas veces se vinculan al acceso a espacios de representación, a trabajos técnicos al interior del Estado o por medio de distribuciones dinerarias que no producen una vinculación directa a las estructuras gubernamentales; pero en todos los casos los recursos provienen del Estado (ya sea nacional o local).

Así, la militancia como actividad a tiempo completo pone en discusión un aspecto central de la vida del militante, el acceso a recursos económicos provenientes del Estado. Cuando el compromiso militante se consolida solo es posible sostenerlo a partir de los propios recursos que brinda la militan-

13 Hace referencia a los planes sociales que se pusieron en marcha en Argentina desde finales de la década del noventa. 
cia; vivir de la militancia o vivir para la militancia son factores comunes que se reproducen en el mundo militante. ${ }^{14}$

Pero la subsistencia en el mundo militante no solo se refiere a una cuestión económica. Otro aspecto clave es la estima pública y el status militante. Es decir, el nivel de reconocimiento que tiene el militante tanto al interior como hacia fuera del mundo. Ser conocido no necesariamente garantiza un status público, pero abre un camino para conformar redes de solidaridades, fidelidades y recursos, incluso accesos a cargos públicos y rentados.

Los militantes utilizan diferentes estrategias para alcanzar un alto status y una estima pública; comienzan a construir un perfil de dirigente en la medida que logran alcanzar un conjunto de lealtades políticas que les garantice el triunfo en un proceso electoral o selección al interior del espacio, pero también que les permita posicionarse ante el poder real, ejerciendo cierta influencia política tanto dentro como fuera del mundo militante. Ese reconocimiento público se logra, mayoritariamente, a partir de configurar un tipo de militancia de base con cercanía a los "no militantes", crear nuevos espacios de representación tanto dentro como fuera de su ámbito original de militancia que se vinculen a las nuevas demandas, o disputar un espacio a otro dirigente al interior de la organización de pertenencia.

Así, el militante pone en marcha una construcción política ${ }^{15}$ que le permite acceder a espacios de decisión y a intervenir en el poder político, al mismo tiempo que configura una disputa al interior del mundo militante y genera interacciones por fuera de ese mundo:

Vos [como militante] te relacionás con la gente, y ellos te reconocen a partir de lo qué hacés para tratar de mejorar o ayudar a aquel que esté en una situación jodida [..], a la larga esa situación te posiciona. (Claudio, Partido Justicialista, septiembre de 2016)

14 Esto no significa que todo militante aspire a ese "vivir de la militancia", pero los distintos entrevistados dan cuenta que un empleo "tradicional" limitaría sus posibilidades de avanzar en su carrera militante.

15 Hay un conjunto de actividades que permite esa construcción política; a partir de las entrevistas realizadas se ha podido detectar que la transversalidad militante (participar en dos o más espacios al mismo tiempo) y construir u ocupar espacios de representación deshabitados, por ejemplo, las áreas de juventud, campesinado e incluso feministas en los partidos, sindicatos o ciertas organizaciones sociales, son elementos clave para esa construcción (Berardi-Spairani, 2017). En este sentido, el militante trata de generar espacios novedosos o reactivar espacios creados anteriormente que fueron abandonados como espacios de participación militante. 
Resolver los problemas, interactuar hacia fuera de las estructuras de participación, vincularse con los no militantes es una manera de crear redes de intercambio que le permiten al militante dar cuenta de su capacidad, del alcance de sus acciones, y de las posibilidades de transformar esos elementos clave para los espacios políticos, sociales o sindicales.

En muchos casos, la transversalidad militante (Berardi-Spairani, 2020b), es decir ocupar más de un espacio de participación, permite crear canales de intercambio y solidaridades que posibilitan la construcción política alcanzando altos grados de estima pública y status militante.

Comenzamos a trabajar en el 2001, formamos parte de un Frente de Desocupados y salimos a la calle a reclamar [...], esa organización permitió que en el partido se convoque a una interna, y luego que nosotros presentamos nuestra lista, hay un consenso con el resto de los compañeros que van bajando la lista y quedaba únicamente la nuestra y la de ellos. (Cecilia, Partido Justicialista, septiembre de 2016)

Antes de entrar al sindicato formé parte del centro vecinal, y después me involucro al Partido Justicialista y empiezo a organizar actividades con los vecinos, $[\ldots]$ pero llego al partido principalmente por mi lugar en el gremio. (Blanca, Unión Trabajadores de Entidades Deportivas y Civiles, septiembre de 2016)

El tema de que estaba la rama de Juventud, el grupo de jóvenes [...], pero para qué servían, para ir a pegar afiches, para repartir panfletos, pero en su momento no estaba en lugares de toma de decisión [...], muchos dirigentes jóvenes se dieron cuenta que movilizar a la juventud, al espacio juvenil servía para influir en el partido. (Claudio, Partido Justicialista Jujuy, marzo de 2016)

Esta construcción política permite mostrar que el mundo militante también es un espacio de disputas, por influir en el sistema político institucional y posicionarse en una batalla por la representación, el sentido y las lógicas de la militancia, por el sostenimiento del status quo o la transformación de ese mundo. Estas disputas se dan tanto al interior de los espacios o ámbitos de participación como fuera de ellos, y la construcción política juega un rol transcendental. Entonces, quienes son dirigentes pueden dejar de serlo, y tener que reconstruir su status militante, estableciendo una nueva estrategia de construcción política. Las distintas voces militantes que aportaron a esta investigación afirman que en muchos casos los dirigentes deben volver al 
"llano", a construir políticamente, a conversar y relacionarse con los otros. La idea de volver al barrio, a conversar con la gente, da cuenta que el rol militante no cambia a pesar de ocupar un lugar dirigencial.

\section{Algunas conclusiones}

Este trabajo se propuso dar cuenta del mundo militante como una herramienta analítica para comprender la forma en que los militantes construyen su carrera a partir de un conjunto de secuencias compartidas, partiendo del análisis de la militancia en la provincia de Jujuy.

A través de los relatos, es posible observar que más allá del espacio de participación política en que desarrollan sus prácticas, los militantes comparten secuencias y/o etapas que son comunes y que deben ser pensadas como lógicas de acción dentro del mundo en el que desarrollan sus prácticas.

Por otra parte, al observar las estrategias que llevan adelante los militantes en su construcción política se pudo constatar que las competencias dentro de ese mundo se establecen a partir de alcanzar espacios de toma de decisiones o la influencia en las políticas de gobierno. La diversidad de esas estrategias muestra que las lógicas de acción son redefinidas en el momento en que los clivajes políticos cambian, que los ámbitos se desarticulan y vuelven a articular producto de la misma coyuntura, poniendo en discusión las prácticas, las tradiciones y las doctrinas.

Si bien no es posible establecer generalidades a partir de este trabajo, sí se puede inducir, por medio de las carreras militante analizadas, que hay elementos que muestran lógicas comunes que hacen a un mundo militante.

Por otra parte, si bien se podría cuestionar que el dirigente de una organización, partido o sindicato integre el mundo militante, los relatos de los entrevistados muestran que, incluso ocupando un lugar de jerarquía dentro de la estructura de participación política, nunca se deja de ser militante. Principalmente porque a partir de los propios cambios generados al interior del mundo (incluso de los espacios de participación) los dirigentes pueden perder su jerarquía y volver a competir por su estatus militante, obligando a establecer nuevas estrategias de construcción política. 


\section{Bibliografía}

Agrikoliansky, E. (2017). Les 'carrières militantes'. Portée et limites d'un concept narratif. En O. Fillieule, F. Haegel, C. Hamidi \& V. Tiberj (dir.), Sociologie plurielle des comportements politiques. Je vote, tu contestes, elle cherche (pp. 167 - 192). Presses de Sciences Po.

Auyero, J. (2002). La protesta. Retratos de la beligerancia popular en la Argentina democrática. Libros del Rojas.

Becker, H. (2008). Los mundos del arte. Sociología del trabajo artístico. Universidad Nacional de Quilmes.

Becker, H. (2009). Trucos del Oficio, como conducir su investigación en ciencias sociales. Siglo XXI Editores.

Becker, H. (2012). Outsider. Siglo XXI Editores.

Berardi-Spairani, A.P. (2017). El mundo militante en la democracia argentina contemporánea: un estudio de trayectorias militantes en la provincia de Jujuy. (Tesis de Doctorado en Sociología). Instituto de Altos Estudios Sociales, Universidad Nacional de San Martín.

Berardi-Spairani, A.P. (2018a). La participación partidaria y el impacto de los contextos políticos. Un estudio de biografías militantes en Jujuy. Estudios Sociales, 55(2), 11-26. https://doi.org/10.14409/es.v55i1.6670

Berardi-Spairani, A.P. (2018b). Carrera militante y construcción política. Un estudio de trayectorias militantes en la provincia de Jujuy. Revista Cuadernos de la Facultad de Humanidades y Ciencias Sociales, 54, 85-144. http:// bit.ly/2AXpVRP

Berardi-Spairani, A.P. (2020a). Participación política, compromiso y carrera militante. Una propuesta para el estudio de la militancia en el contexto del activismo global. Desafios, 32(2), 1-37. https://doi.org/10.12804/revistas.urosario.edu.co/desafios/a.7751

Berardi-Spairani, A.P. (2020b). La transversalidad militante y la participación política. Revista Mexicana de Sociología, 82(3), 645-672. https://bit. ly/3iyNHY3

Bourdieu, P. (1989). Prerrequisitos críticos y principios de método. Criterios, 2528, 20-42. http://bit.ly/2or6AFW

Bourdieu, P (2007). El sentido práctico. Siglo XXI Editores.

Burawoy, M. (1998) The Extended Case Method. Sociological Theory, 1, 4-33.

Canelo, P. (2001). ¿Dónde está el enemigo?: la rearticulación menemista de los clivajes políticos y la disolución del antagonismo social. Argentina, 1989- 
1995. Informe del concurso Culturas e identidades en América Latina y el Caribe. Programa Regional de Becas CLACSO. http://bit.ly/2AUWYWz

Della Porta, D. (2014). Methodological Practices in Social Movement Research. Oxford University Press.

Diani, M. (2004). Networks and Participation. En D. Snow, S. Soule, \& H. Kriesi (Ed.), The Blackwell Companion To social movements (pp. 339-359). Blackwell Publishing Ltd.

Dubet, F. (1994). Sociologie de l'expérience. Seuil.

Fillieule, O. (2001). Propositions pour une analyse processuelle de l'engagement individuel. Revue française de science politique, 51, 199-215. https://doi. org.10.3917/rfsp.511.0199

Fillieule, O., \& Accornero, G. (2016). Introduction. So many as the stars of the sky in multitude, and as the sand which is by the sea shore innumerable: European Social Movement Research in Perspective. En O. Fillieule, \& G. Accornero (Ed.), Social Movement Studies in Europe. The State of the Art (pp. 1-20). Berghahn Books.

Frederic, S. (2004). Buenos vecinos, malos políticos. Moralidad y política en el Gran Buenos Aires. Prometeo.

Klandermans, B. (2004). The demand and supply of participation: Social psychological correlates of participation in social movements. En D. Snow, S. Soule, \& H. Kriesi. (Ed.), The Blackwell Companion to Social Movements (pp. 360-379). Wiley-Blackwell.

Gaxie, D. (1977). Economie des partis et retribution du militantisme. Revue française de science politique, 27(1), 123-154. https://doi.org.10.3406/ rfsp.1977.393715

Giorgi, G. I. (2014). Los factores “extrapolíticos” de la carrera política: una aproximación a las sociabilidades de los ministros de la Nación en la Argentina (1854-2011). Política, 52(2), 243-275. https://doi.org.10.5354/07161077.2015.36158

Jelin, E. (Comp.) (1985). Los nuevos movimientos sociales 2. CEAL.

Kornblit, A.L. (Coord.) (2007). Metodologías cualitativas en ciencias sociales. Modelos y procedimientos de análisis. Biblos.

Levita, G. (2015). La política como profesión: perfiles y tipos de trayectorias de los senadores argentinos. Telos, 17(1), 38-57. http://bit.ly/2B0wG5e

Lodola, G. (2009). La estructura subnacional de las carreras políticas en Argentina y Brasil. Desarrollo Económico, 194(49), 247-286. 
McAdam, D. (1982). Political process and development of black isurgency, 19301970. The University of Chicago Press.

Meccia, E. (2012). Subjetividades en el puente. El método biográfico y el análisis microsociológico del tránsito de la homosexualidad a la gaycidad. Revista Latinoamericana de Metodología en Investigación Social, 4, 38-51. http://bit.ly/311e7IW

Meccia, E. (2015). Cambio y narración. Las transformaciones de la homosexualidad en Buenos Aires según los relatos de homosexuales mayores. Sexualidad, Salud y Sociedad. Revista Latinoamericana, 19, 11-43. https://doi. org.10.1590/1984-6487

Morán, M.L. (2011). La cultura política de las mujeres. Un campo de estudio todavía por explorar. Psicología Política, (42), 45-68. https://bit.ly/2YcwcoC

Murillo, M.V.(2013). Cambio y continuidad del sindicalismo en democracia. SAAP, 7(2), 339-348. http://bit.ly/2MqO715

Peller, M. (2018). Las paradojas de la revolución. Figuraciones del cuerpo en la prensa del PRT-ERP en la Argentina de los años setenta. Izquierdas, 41, 77-99. https://bit.ly/3fODUeL

Pereyra, S. (2008). ¿La Lucha es una sola? Biblioteca Nacional, Universidad Nacional de General Sarmiento.

Pereyra, S., \& Berardi, A. (2020). El compromiso político en las víctimas. En M. Pita y S. Pereyra, (Ed.), Movilización de víctimas y demandas de justicia (pp.179-230). Teseo Press.

Pudal, B. (2011). Los enfoques teóricos y metodológicos de la militancia. Revista de Sociología, 25, 17-35. https://doi.org.10.5354/0716-632X.2011.27495

Quirós, J. (2006). Cruzando la Sarmiento. Una etnografía sobre piqueteros en la trama social del sur del Gran Buenos Aires. IDES.

Saltalamacchia, H. (1987). Historia de vida y movimientos sociales: el problema de la representatividad (Apuntes para la reflexión). Revista Mexicana de Sociología, 49(1), 255-277. http://bit.ly/2OACL0q

Svampa, M., \& Pereyra, S. (2004). Entre la ruta y el barrio. La experiencia de las organizaciones piqueteras. Biblos.

Vázquez, M. (2010). Socialización política y activismo. Carreras de militancia política de jóvenes referentes de un movimiento de trabajadores desocupados. (Tesis de Doctorado en Ciencias Sociales). Universidad de Buenos Aires-Facultad de Ciencias Sociales.

Vommaro, G., Morresi, S., \& Bellott, A. (2015). Mundo PRO: Anatomía de un partido hecho para ganar. Planeta. 
Zenobi, D., \& Pereyra, V. (2015). "Familiares de detenidos y expertos del derecho: trayectorias y carreras militantes en la construcción de una causa pública" [en línea]. Ponencia presentada en la XI Reunión de Antropología del Mercosur, 30 de noviembre-4 de diciembre, Montevideo, Uruguay. http://bit.ly/35gOzLn.

Fechas de envío: 2019/II/02; Fecha de aceptación: 2020/08/II;

Fecha de publicación: 2020/09/0I 